\title{
Prevalence and clinical characteristics of rheumatoid arthritis in Poland: a nationwide study
}

\author{
Bogdan Batko ${ }^{1}$, Marcin Stajszczyk ${ }^{2}$, Jerzy Świerkot ${ }^{3}$, Karol Urbański ${ }^{4}$, Filip Raciborski ${ }^{5}$, \\ Mariusz Jędrzejewski ${ }^{6}$, Piotr Wiland ${ }^{3}$
}

\author{
'Department of Rheumatology, J. Dietl Specialist Hospital, Krakow, Poland \\ ${ }^{2}$ Rheumatology and Autoimmune Diseases Department, Silesian Rheumatology \\ Center, Ustron, Poland \\ ${ }^{3}$ Department of Rheumatology and Internal Medicine, Wroclaw Medical University, \\ Wroclaw, Poland \\ ${ }^{4}$ Department of Internal and Agricultural Medicine, Jagiellonian University School \\ of Medicine, Krakow, Poland \\ ${ }^{5}$ Department of Prevention of Environmental Hazards and Allergology, \\ Medical University of Warsaw, Poland \\ ${ }^{6} \mathrm{GfK}$ Polonia, Warsaw, Poland
}

Submitted: 9 August 2017

Accepted: 13 October 2017

Arch Med Sci 2019; 15, 1: 134-140

DOI: https://doi.org/10.5114/aoms.2017.71371

Copyright $\odot 2017$ Termedia \& Banach

\section{Abstract}

Introduction: There are no reliable data regarding the prevalence of rheumatoid arthritis (RA) in Poland.

Material and methods: The first stage was a face-to-face survey on a nationwide representative sample of 3000 people, which identified respondents with a physician-confirmed diagnosis of RA. The second stage was a survey of RA patients, which characterized the disease course and treatment. It was evaluated by analysis of a representative group of 1957 RA patients in routine clinical practice. Results: The overall RA prevalence in Poland was $0.9 \%$ ( $95 \% \mathrm{Cl}: 0.6-1.2 \%)$, $1.06 \%$ for women, $0.74 \%$ for men. Seventy-eight percent were female, mean age was 56 and mean disease duration 7 years. Younger patients $(<50)$ remained professionally active in $90 \%$ of cases. Thirty percent of patients were diagnosed within 3 months of the first RA symptoms, while for $17 \%$ it took more than 1 year. Fifty-six percent of newly diagnosed patients were characterized by high disease activity (DAS-28 $>5.1$ ). Presently, low disease activity (DAS- $28<3.2$ ) was found in $38.5 \%$ of patients. In Poland, $94 \%$ of patients have been treated with non-steroid anti-inflammatory drugs, almost $80 \%$ with glucocorticoids. Meanwhile, methotrexate, as an anchor drug in Poland, has been used by $80 \%$ of patients, biological agents by $2.94 \%$ of patients.

Conclusions: This is the first cross-sectional population-based epidemiological study regarding prevalence of RA in the adult Polish population. The results demonstrate a high prevalence, falling within the upper boundary estimates for Europe. Despite ongoing treatment, the majority still have moderate to high disease activity, and the use of biological therapies is low.

Key words: rheumatoid arthritis, disease activity, epidemiology, diseasemodifying anti-rheumatic drugs.

\section{Introduction}

Rheumatoid arthritis (RA) is a chronic autoimmune disease, with a tendency to result in progressive joint damage and systemic complications.

\author{
Corresponding author: \\ Bogdan Batko MD, PhD \\ Department \\ of Rheumatology \\ J. Dietl \\ Specialist Hospital \\ 1 Skarbowa St \\ 31-121 Krakow, Poland \\ Phone: +48 603686744 \\ E-mail: bpbatko@gmail.com
}


Organ damage secondary to RA progression can lead to disability and premature death [1]. Epidemiological data are needed for health professionals and policy makers to ensure an appropriate health care system. The prevalence of RA varies between countries with a significant increase from southern to northern regions: $0.33 \%$ in Italy [2], $0.31 \%$ in France [3], $0.8 \%$ in Finland [4], and $0.85 \%$ in England [5]. It is proposed that the geographical variability is associated with the severity of the disease [6]. Other differences are observed based on ethnicity. For instance, no cases of RA were diagnosed in the rural Nigerian population [7], whereas Pima Indians from Arizona are known for an exceptionally high RA incidence rate [8].

A compelling observation is that overall RA prevalence has shown a declining tendency over the last few decades $[9,10]$, more visible in female disease distribution. Nevertheless, an increase of disease incidence due to ageing can be noted [11]. The incidence changes can be explained to an extent by different classification criteria over the years, when comparative studies were performed at different time points. The 1987 revised RA classification criteria caused a decrease of incidence by over $20 \%$ in the UK [5]. However, a systematic review based on the same criteria shows a surprisingly increasing RA prevalence in low- and middle-income countries [12].

While there are multiple studies in other European countries, we still lack nationwide epidemiological data in Poland. The health care system in our country is based on general practitioners (GPs), who are usually the first line physician the patients meet. Based on the symptoms and results of basic tests, patients are referred to a specialist when necessary. In Poland, it often takes a few months to be seen by a specialist. Meanwhile, according to guidelines, the treatment of RA should be initiated as soon as possible to achieve longstanding remission and reduce detrimental effects of the disease $[13,14]$. Not only prevalence, but also the course of the disease has been reported to differ between the regions, with northern countries being associated with more severe disease [6, 15]. Different causes of this phenomenon are raised such as genetic variants of HLA-DRB1 [16, 17] or differences in socioeconomic status [18]. The mentioned data indicate substantial cross-population differences in the course of the disease and are not fully comparable to each other. That is why the RA prevalence data in Poland are so eagerly anticipated. Hence, it would be optimal to align the health system with real demands.

Our study consisted of two stages. The objective of the first was to obtain reliable data on the RA prevalence rate in Poland. The second stage consisted of the analysis of RA patients with regard to disease activity and type of treatment. This information provides insight into clinical characteristics and effectiveness of therapy. Recently published data indicate substantial differences between urban and rural areas in Poland, with a morbidity rate of 5-8 and 3.7-4 per 1000 inhabitants respectively [19]. The authors suggest that it may result from restricted access to rheumatologists and a higher proportion of undiagnosed patients. This underlines the need for reliable data to improve health care for RA patients in Poland.

\section{Material and methods}

\section{Cross-sectional study}

The first stage was carried out on a representative, nation-wide group of 3000 people aged 15 years or more. The study was conducted under the Omnibus profile. Random-quota sample selection was performed through the personal identification database (PESEL), with each ID having equal sampling probability. Each Polish citizen has his own PESEL number, so the sample was chosen from all Polish citizens. In the case of no response of the chosen person, another one was recruited from the same district of the same sex and age group. No additional conditions were considered in the selection process. The distribution of the sample reflects the country demographics, including sex, education and place of residence. Quantitative data were collected from a sample of 3000 persons, the sample size chosen to be reflective of the general Polish population, requirements of the Omnibus program and researcher resources. Each participant was visited face-to-face by a trained interviewer. The questionnaire was validated for the Polish RA population, and included questions regarding: (a) chronic conditions, (b) joint symptoms (pain, swelling, morning stiffness exceeding $1 \mathrm{~h}$, motion restriction), (c) distribution of peripheral joint pain or swelling - recorded on the diagram, (d) present diagnosis of arthritis, (e) specialization of the physician stating diagnosis and current attending physician, (f) drug use for joint symptoms (type, dosage, route of administration, treatment period). Patients may be unaware of conditions they suffer from, which could further confuse the proper diagnosis. In order to rectify this, questions were repeated several times in a different manner, adopting alternative nomenclature for symptoms and disease. Moreover, questions referred to the current clinical state; therefore, well-treated persons presented few to no symptoms. To overcome this underestimation, only patients with a diagnosis confirmed by a specialist were taken into account. On the other hand, this approach underes- 
A

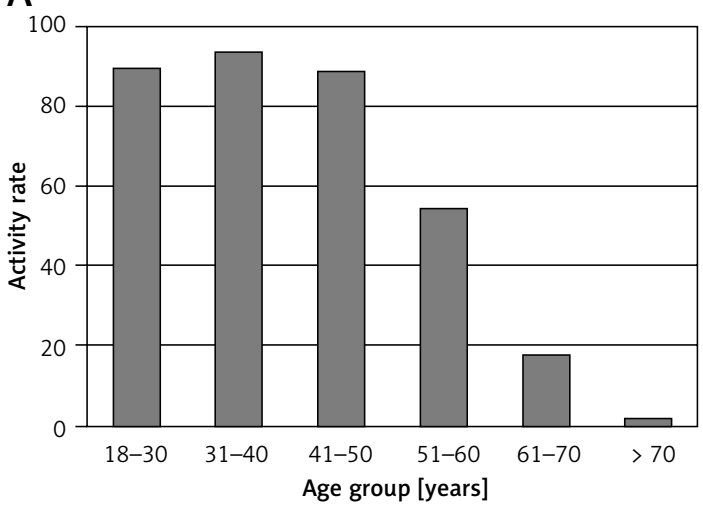

B

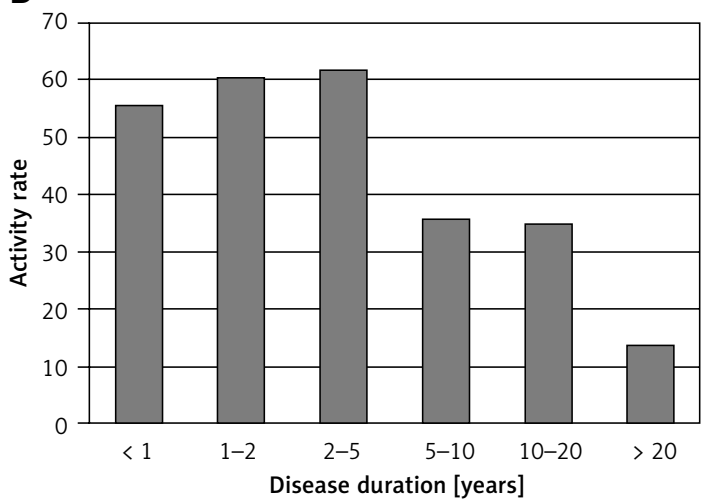

Figure 1. Economic activity of RA patients, by age (A) and disease duration (B)

timates patients with symptoms still undiagnosed by a physician. The method was validated on two groups, 50 participants each, with confirmed RA and a control group without RA.

\section{Analysis of patients with diagnosed rheumatoid arthritis}

A hundred rheumatologists with at least 5-year experience completed detailed questionnaires about 20 sequential patients, each diagnosed with RA. Data were gathered between December 2014 and February 2015 from 1957 patients. Physicians were chosen based on the centers they work in (based on information from the Polish Chamber of Physicians), so as to reflect the national structure of RA treatment in Poland. During data analysis overrepresentation of centers with biological treatment was observed. The problem arose from the fact that even though physicians were recruited in a center without biological treatment, they also worked in a facility with such treatment possibilities and could enroll those patients. It was overcome by giving such physicians appropriate weights. The questionnaire consisted of both closed and open-ended questions, reflecting among other things: (a) the diagnostic process,

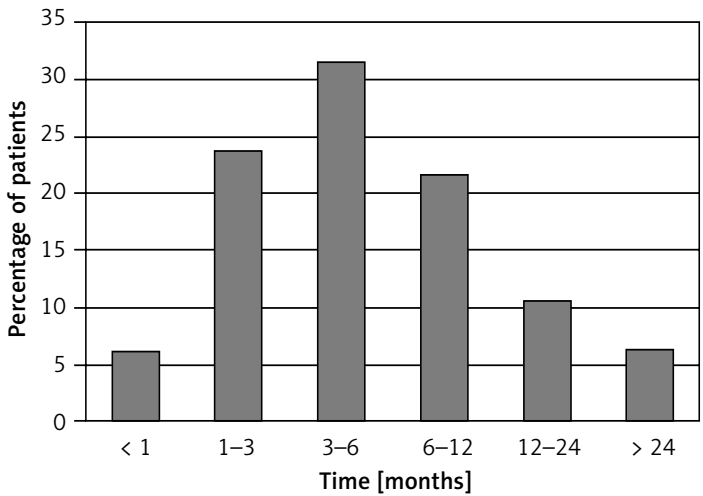

Figure 2. Time from beginning of symptoms to proper diagnosis (b) indicators of RA activity at diagnosis and currently, (c) employment status, (d) medicines currently and previously used.

Ethical approval by decree of the Local Ethics Committee (Decision No. L.dz.OIL/KBL/OIL/9/214) and informed consent in accordance with the Helsinki Declaration was obtained.

\section{Results}

\section{Characteristics of patients}

The first stage of the study revealed that overall RA prevalence in Poland was $0.9 \%(95 \% \mathrm{Cl}$ : 0.6-1.2\%), $1.06 \%$ for women and $0.74 \%$ for men. In the second stage, a total of 1957 patients with RA were analyzed, of whom $78 \%$ were female. The mean age was $56.77 \pm 13.9$ (SD) years old. The mean disease duration was approximately 7 years, with $56 \%$ of patients diagnosed within the last 5 years, after the appearance of the new EULAR/ ACR classification criteria. The ratio of economically active to inactive patients from the ages of 51-60 was almost $1: 1$; however, younger patients $(<50)$ remained professionally active in approximately $90 \%$ of cases. Moreover, with a disease duration over 5 years, the activity rates did not exceed 36\% (Figure 1).

\section{Time from symptoms to diagnosis}

The mean time from onset of symptoms to first medical contact was ca. 3.5 months. In Poland $71 \%$ of patients with RA were first seen by their GP, $13 \%$ by an internist, $10 \%$ by a rheumatologist, and the remainder by other specialists. Overall, $30 \%$ of patients were diagnosed within 3 months from symptom onset but for $17 \%$ it took over 1 year. The diagnosis of RA took approximately 9 months on average (Figure 2).

\section{Characteristics of the disease}

The patients were screened for disease activity at the time of diagnosis and when performing 
Table I. Indicators of RA activity, at time of diagnosis and current

\begin{tabular}{|c|c|c|c|c|}
\hline \multicolumn{3}{|l|}{ Variable } & At diagnosis & At last visit \\
\hline \multicolumn{2}{|c|}{ Tender joint count } & Median (min, max) & $8(1,16)$ & $2(0,12)$ \\
\hline \multicolumn{2}{|c|}{ Swollen joint count } & & $4(1,15)$ & $1(0,10)$ \\
\hline \multicolumn{2}{|l|}{ DAS28-ESR } & & $5.2(3.0,8.8)$ & $3.7(0.6,8.2)$ \\
\hline \multirow[t]{4}{*}{ DAS28-ESR } & $\leq 2.6$ & $\%$ patients & 0 & 26.1 \\
\hline & $2.61-3.2$ & & 1.5 & 12.4 \\
\hline & $3.21-5.1$ & & 42.7 & 50.7 \\
\hline & $>5.1$ & & 56.0 & 10.8 \\
\hline
\end{tabular}

the survey. $56 \%$ of newly diagnosed patients were characterized by a high disease activity of DAS$28>5.1$. Presently, low disease activity of DAS-28 $<3.2$ was found in nearly $40 \%$ of patients; however, there was still a majority with DAS-28 > 3.2 who had not achieved the goals of the RA treatment guidelines (Table I).

\section{Methods of treatment}

The main SDMARD (synthetic disease-modifying anti-rheumatic drug) is methotrexate, which was used at some time by $91 \%$ of patients (Table II). Other frequently used drugs were sulfasalazine, leflunomide, and antimalarial drugs, with the occasional use of cyclosporine and gold salts. However, hydroxychloroquine and gold salts are not available on the Polish market. Seventy-five percent of patients were subject to glucocorticoid therapy, with $42 \%$ of patients continuing said therapy. The second most common drug group after methotrexate was non-steroidal anti-inflammatory drugs (NSAIDs). Nearly every patient was subject to NSAID treatment, with a recorded $59 \%$ receiving them at the time of the survey. Diclofenac was the most common choice, used by one fourth of the patients. Only $2.9 \%$ of patients are currently treated with biological agents both reimbursed by the National Health Fund and having undergone clinical trials.

\section{Discussion}

This is the first cross-sectional, populationbased epidemiological study regarding RA in the adult Polish population. The results demonstrate a high prevalence of RA. They fall within the upper bound estimates for Europe, but are double the values from model-based estimates calculated for Poland by Kobelt and Kasteng [20]. Thus, according to the south-north paradigm, Poland should be classified as a northern country. At the same time we should keep in mind that the observed differences are recently being questioned as statistically insignificant [21]. Second stage sex dis- tribution of Polish RA patients is 3.5 : 1 (female: male), slightly higher than reported in other countries, though still consistent with other data from Poland [19] presented by Iltchev et al. That study compared RA prevalence in rural and urban areas in Poland but was based on information from the National Health Fund, included rheumatologist confirmed disease and did not include patients diagnosed in private medical practices. It showed an increasing morbidity rate of RA between 20082012 from 4.6 to 6 per 1000 inhabitants, which was in part explained by the new 2010 diagnostic criteria. In contrast, we based our results on a representative nation-wide group of people irrespective of the type of health care system the patient uses. Our results show even higher prevalence of $0.9 \%$. It may be caused by an increasing burden of RA but also by underestimation of the previous study. Hence, because of the different methodology, comparing them in time and drawing conclu-

Table II. Type of RA treatment, currently and previously used

\begin{tabular}{|c|c|c|}
\hline Variable & $\begin{array}{l}\text { Currently } \\
\text { used }\end{array}$ & $\begin{array}{c}\text { Previously } \\
\text { used }\end{array}$ \\
\hline \multicolumn{3}{|l|}{ Synthetic DMARDs: } \\
\hline Methotrexate & 80.18 & 91.11 \\
\hline Sulfasalazine & 14.43 & 41.17 \\
\hline Leflunomide & 7.03 & 13.85 \\
\hline $\begin{array}{l}\text { Chloroquine/ } \\
\text { hydroxychloroquine }\end{array}$ & 4.14 & 13.65 \\
\hline Cyclosporine & 1.29 & 5.71 \\
\hline Gold salts & 0.22 & 4.18 \\
\hline $\begin{array}{l}\text { Biological DMARDs } \\
\text { (in total)*: }\end{array}$ & 2.94 & 4.66 \\
\hline Glucocorticoids & 42.48 & 75.48 \\
\hline NSAIDs & 58.9 & 94.08 \\
\hline
\end{tabular}

*Treatment reimbursed by the National Health Fund and conducted clinical trials. Values indicate $\%$ of patients treated with a given drug 
sions about changes in disease prevalence in such short period should be undertaken with caution. As mentioned earlier, the decrease in prevalence of the disease, observed in the recent half century, can be partially attributed to implementation of the 1987 revised ACR criteria. However, a reverse trend can be observed with the appearance of the new 2010 ACR/EULAR criteria, which enable early-stage RA diagnosis. Nowadays, there are projections of an increase in RA prevalence [22], which can be linked to an increase in life expectancy. As a result, patients diagnosed years ago live longer and do not decrease the disease prevalence rate, while new cases occur as usual and increase the number of patients. Our study does not have sufficient statistical power to calculate prevalence in different age groups, which is restricted to registries. Although the age structure in our study shows that the majority of RA patients are in their sixties, they still fall within the younger percentiles for Europe [20]. Moreover, register data from Sweden, characterized by longevity, show that crude and age-adjusted prevalence rates do not differ considerably [23].

GPs fulfill the central role in the Polish healthcare system. According to our data, in $71 \%$ of cases they are the first medical contact of the patient after symptom onset. They order basic tests and refer the patient to a specialist, who in $90 \%$ of RA diagnoses is a rheumatologist. Insurance conditions in Poland limit the number of diagnostic procedures that can be conducted by a GP, of which anti-cyclic citrullinated peptide antibodies, other antibodies as well as imaging tests such as ultrasonography of joints, computed tomography and magnetic resonance imaging studies are restricted to specialists. After diagnosis, GPs mainly continue the treatment prescribed by a rheumatologist and deal with minor concerns (data not shown). Modification of chronic treatment is reserved for specialists.

Time is of uppermost importance; diagnosis of RA should be established quickly to implement effective treatment - not only to relieve the symptoms but especially to halt joint damage, which may occur as early as the first few months [24], as well as to slow down occurrence of RA complications [25]. We can obtain highly successful treatment of RA especially within 3 months of disease duration [26]. In our study, for nearly half of the patients, more than 2 months pass until the first contact with a physician occurs. Approximately 9 months pass on average before the RA diagnosis is established. In order to improve the situation, a change must occur in patient awareness of the importance of the first arthritic symptoms and the necessity for physician consultation as early as possible. Lag times differ from country to country. In Spain the first rheumatologist encounter occurs after 17 months from symptom onset [27]. In a Canadian study $22 \%$ of patients received DMARDs within 3 months and $48 \%$ within 6 months, which is less than in our study. However, the median lag time was shorter (6.4 months). It suggests a greater number of patients with very long lag times in our study. In other studies lag time delays were 4 months in Norway [28] and 9 months in the United States [29]. In contrast, in Venezuela the lag time between symptom onset and RA diagnosis was as long as 40 months [30]. The main cause of these differences mentioned by all authors is the number of and access to rheumatologists.

According to Kobelt's et al. report [20], Poland is close to the European average regarding numbers of RA patients per rheumatologist. It should be noted that for Poland Kobelt's et al. estimate was $0.49 \%$, while our data indicate a nearly doubled RA prevalence rate of $0.9 \%$. After this adjustment, with about 300 RA patients per rheumatologist, we have one of the lowest indices in Europe. Moreover, the prediction for the upcoming years is not favorable. In $2009,30 \%$ of rheumatologists were over 60 years old [31]. Earlier retirement age may further increase the shortage of rheumatologists in the future.

The primary form of RA treatment rests upon conventional sDMARDs. The anchor drug in Poland is methotrexate, which is in accordance with current guidelines indicating it as the first line treatment. Other DMARDs are much less frequently used, with the exception of sulfasalazine, which was used at some point by $40 \%$ of patients. Non-steroid antiinflammatory drugs and glucocorticosteroids are very frequently used by RA patients. The COMORA study gave similar results, although high international variability was observed [32].

Most NSAIDs (excluding ibuprofen) are available in Poland mainly upon prescription, which prevents excessive and inappropriate use. These drug groups are considered symptomatic drugs and should only be used for a limited period of time. The goal is to control the disease through use of DMARDs, while chronic NSAID use may be regarded as treatment failure. Indeed, at the last visit over $60 \%$ of patients had high or intermediate disease activity in DAS28-ESR and did not fulfill disease control criteria. The results of our study suggest a necessity for optimizing the treatment strategy, with synthetic and biological DMARDs. Unfortunately, the use of biological agents in Poland is low $(2.9 \%$, of which $13 \%$ are in clinical trials), while in Sweden it applies to one fourth of RA patients [23]. Compared to other European countries, Poland has one of the lowest indices of biological treatment [20]. The main cause of 
this situation is too little funds allocated to this kind of treatment. Criteria which must be met to get expensive biological drugs refunded in Poland are restrictive and not all patients can be treated according to guidelines. For a certain group of patients, biologic treatment may be the only opportunity for improved disease control, reduced symptomatic drug use and a resulting improvement in quality of life and employment. The loss in economic activity is observed after 5 years of disease duration and in the sixth decade of life (Figure 1). For younger RA patients $(<50$ years old) activity rates are comparable to the overall population based on data available from the Central Statistical Office and Eurostat, but in the sixth and seventh decades they are decreased, with the biggest fall concerning people in their fifties (sixth decade $-54.4 \%$ RA vs. $69.7 \%$; seventh decade $17.7 \%$ RA vs. $20.3 \%$ ).

The strength of the first stage of the study lies in the methodological approach with a face-toface interview, which allows for a more comprehensive interview of the patient (compared to telephone surveys), followed by a recorded confirmation of current drugs (including DMARDs) in use. Moreover, only respondents with a specialist-confirmed diagnosis of RA were considered in the data, rheumatologists constituting $98 \%$ of them - the resulting limitation being the $2 \%$ of patients for whom the diagnosis was made by a specialist other than a rheumatologist, with no secondary confirmation. An apparent limitation is the second part of the study, being a retrospective analysis. Furthermore, the changing classification criteria throughout patient observation impact the precision of results concerning diagnosis.

In conclusion, this is a unique epidemiological study in the Polish population, which demonstrates higher prevalence of RA in comparison to previously calculated estimates, and is therefore crucial for policymakers devising a healthcare system. Retrospective analysis indicates a necessity for earlier diagnosis and optimization of therapy accordingly, since the majority of patients still exhibit moderate to high disease activity. Achieving this requires constructive education of first contact physicians and patients in terms of symptom significance and disease characteristics, coinciding with an improvement of access to consultation with a rheumatologist.

\section{Acknowledgments}

The study was supported by Roche. A special thanks goes to all the physicians who made this study possible.

\section{Conflict of interest}

The authors declare no conflict of interest.

\section{References}

1. Kucharz EJ. Reumatoidalne zapalenie stawów. In: Wielka Interna: Reumatologia. $2^{\text {nd }}$ ed. Puszczewicz M (ed.). Medical Tribune, Warsaw 2016.

2. Cimmino MA, Parisi M, Moggiana G, Mela GS, Accardo S. Prevalence of rheumatoid arthritis in Italy: the Chiavari Study. Ann Rheum Dis 1998; 57: 315-8.

3. Guillemin F, Saraux A, Guggenbuhl P, et al. Prevalence of rheumatoid arthritis in France: 2001. Ann Rheum Dis 2005; 64: 1427-30.

4. Hakala M, Pöllänen R, Nieminen P. The ARA 1987 revised criteria select patients with clinical rheumatoid arthritis from a population based cohort of subjects with chronic rheumatic diseases registered for drug reimbursement. J Rheumatol 1993; 20: 1674-8.

5. Symmons D, Turner G, Webb R, et al. The prevalence of rheumatoid arthritis in the United Kingdom: new estimates for a new century. Rheumatology (Oxford) 2002; 41: 793-800.

6. Salvarani C, Macchioni P, Mantovani W, et al. Extraarticular manifestations of rheumatoid arthritis and HLA antigens in northern Italy. J Rheumatol 1992; 19: 242-6.

7. Silman AJ, Ollier W, Holligan S, et al. Absence of rheumatoid arthritis in a rural Nigerian population. J Rheumatol 1993; 20: 618-22

8. Del Puente A, Knowler WC, Pettitt DJ, Bennett PH. High incidence and prevalence of rheumatoid arthritis in Pima Indians. Am J Epidemiol 1989; 129: 1170-8.

9. Dugowson CE, Koepsell TD, Voigt LF, Bley L, Nelson JL, Daling JR. Rheumatoid arthritis in women. Incidence rates in group health cooperative, Seattle, Washington, 1987-1989. Arthritis Rheum 1991; 34: 1502-7.

10. Spector TD, Hart DJ, Powell RJ. Prevalence of rheumatoid arthritis and rheumatoid factor in women: evidence for a secular decline. Ann Rheum Dis 1993; 52: 254-7.

11. Uhlig T, Kvien TK. Is rheumatoid arthritis disappearing? Ann Rheum Dis 2005; 64: 7-10.

12. Rudan I, Sidhu S, Papana A, et al. Prevalence of rheumatoid arthritis in low- and middle-income countries: a systematic review and analysis. J Glob Health 2015; 5: 010409.

13. Ramiro S, Gaujoux-Viala C, Nam JL, et al. Safety of synthetic and biological DMARDs: a systematic literature review informing the 2013 update of the EULAR recommendations for management of rheumatoid arthritis. Ann Rheum Dis 2014; 73: 529-35.

14. Singh JA, Saag KG, Bridges SL, et al. 2015 American College of Rheumatology Guideline for the Treatment of Rheumatoid Arthritis. Arthritis Care Res (Hoboken) 2016; 68: 1-25.

15. Drosos AA, Lanchbury JS, Panayi GS, Moutsopoulos HM. Rheumatoid arthritis in Greek and British patients. A comparative clinical, radiologic, and serologic study. Arthritis Rheum 1992; 35: 745-8.

16. Gonzalez-Gay MA, Garcia-Porrua C, Hajeer AH. Influence of human leukocyte antigen-DRB1 on the susceptibility and severity of rheumatoid arthritis. Semin Arthritis Rheum 2002; 31: 355-60.

17. Del Rincón I, Battafarano DF, Arroyo RA, Murphy FT, Fischbach $M$, Escalante A. Ethnic variation in the clinical manifestations of rheumatoid arthritis: role of HLADRB1 alleles. Arthritis Rheum 2003; 49: 200-8.

18. Dadoniene J, Uhlig T, Stropuviene S, Venalis A, Boonen A, Kvien TK. Disease activity and health status in rheumatoid arthritis: a case-control comparison between Norway and Lithuania. Ann Rheum Dis 2003; 62: 231-5.

19. Iltchev P, Śliwczyński A, Czeleko T, et al. Epidemiology of rheumatoid arthritis (RA) in rural and urban areas of 
Poland - 2008-2012. Ann Agric Environ Med 2016; 23: 350-6.

20. Kobelt G, Kasteng F. Access to innovative treatments in rheumatoid arthritis in Europe. A report prepared for the European Federation of Pharmaceutical Industry Associations (EFPIA). Lund University (Sweden) 2009.

21. Alamanos Y, Voulgari PV, Drosos AA. Incidence and prevalence of rheumatoid arthritis, based on the 1987 American College of Rheumatology criteria: a systematic review. Semin Arthritis Rheum 2006; 36: 182-8.

22. Hootman JM, Helmick CG. Projections of US prevalence of arthritis and associated activity limitations. Arthritis Rheum 2006; 54: 226-9.

23. Englund M, Jöud A, Geborek P, Felson DT, Jacobsson LT, Petersson IF. Prevalence and incidence of rheumatoid arthritis in southern Sweden 2008 and their relation to prescribed biologics. Rheumatology (Oxford) 2010; 49: 1563-9.

24. Machold KP, Stamm TA, Nell VP, et al. Very recent onset rheumatoid arthritis: clinical and serological patient characteristics associated with radiographic progression over the first years of disease. Rheumatology (Oxford) 2007; 46: 342-9.

25. Raczkiewicz A, Juszkiewicz A, Kisiel B, et al. Treat-to-target therapy does not prevent excessive progression of carotid intima media thickness during the first year of therapy in early rheumatoid arthritis. Arch Med Sci Atheroscler Dis 2016; 1: e36-43.

26. Nell VP, Machold KP, Eberl G, Stamm TA, Uffmann M, Smolen JS. Benefit of very early referral and very early therapy with disease-modifying anti-rheumatic drugs in patients with early rheumatoid arthritis. Rheumatology (Oxford) 2004; 43: 906-14.

27. Hernández-García C, Vargas E, Abásolo L, et al. Lag time between onset of symptoms and access to rheumatology care and DMARD therapy in a cohort of patients with rheumatoid arthritis. J Rheumatol 2000; 27: 2323-8.

28. Palm $\varnothing$, Purinszky E. Women with early rheumatoid arthritis are referred later than men. Ann Rheum Dis 2005; 64: 1227-8.

29. Chan KW, Felson DT, Yood RA, Walker AM. The lag time between onset of symptoms and diagnosis of rheumatoid arthritis. Arthritis Rheum 1994; 37: 814-20.

30. Rodríguez-Polanco E, Al Snih S, Kuo YF, Millán A, Rodríguez MA. Lag time between onset of symptoms and diagnosis in Venezuelan patients with rheumatoid arthritis. Rheumatol Int 2011; 31: 657-65.

31. Drapala A, Grabowska-Wozniak E, Gryglewicz J, et al. Stan opieki reumatologicznej w Polsce. Streszczenie raportu projektu badawczego (Condition of rheumatological care in Poland. Abstract of a study project report). Uczelnia Łazarskiego, Warszawa 2011.

32. Dougados M, Soubrier M, Antunez A, et al. Prevalence of comorbidities in rheumatoid arthritis and evaluation of their monitoring: results of an international, cross-sectional study (COMORA). Ann Rheum Dis 2014; 73: 62-8. 